This is the author's final, peer-reviewed manuscript as accepted for publication. The publisher-formatted version may be available through the publisher's web site or your institution's library.

\title{
Evolutionary characterization of pig interferon-inducible transmembrane gene family and member expression dynamics in tracheobronchial lymph nodes of pigs infected with swine respiratory disease viruses
}

Laura C. Miller, Zhihua Jiang, Yongming Sang, Gregory P. Harhay and Kelly M. Lager

\section{How to cite this manuscript}

If you make reference to this version of the manuscript, use the following information:

Miller, L. C., Jiang, Z., Sang, Y., Harhay, G. P., \& Lager, K. M. (2014). Evolutionary characterization of pig interferon-inducible transmembrane gene family and member expression dynamics in tracheobronchial lymph nodes of pigs infected with swine respiratory disease viruses. Retrieved from http://krex.ksu.edu

\section{Published Version Information}

Citation: Miller, L. C., Jiang, Z., Sang, Y., Harhay, G. P., \& Lager, K. M. (2014). Evolutionary characterization of pig interferon-inducible transmembrane gene family and member expression dynamics in tracheobronchial lymph nodes of pigs infected with swine respiratory disease viruses. Veterinary Immunology and Immunopathology, 159(3-4), 180-191.

Copyright: Published by Elsevier B.V.

Digital Object Identifier (DOI): doi:10.1016/j.vetimm.2014.02.015

Publisher's Link: http://www.sciencedirect.com/science/article/pii/S0165242714000518

This item was retrieved from the K-State Research Exchange (K-REx), the institutional repository of Kansas State University. K-REx is available at http://krex.ksu.edu 


\title{
Evolutionary Characterization of Pig Interferon-inducible Transmembrane Gene Family and Member Expression Dynamics in Tracheobronchial Lymph Nodes of Pigs Infected with Swine Respiratory Disease Viruses
}

\author{
Laura C. Miller* ${ }^{1}$, Zhihua Jiang ${ }^{* 2}$, Yongming Sang* ${ }^{3}$, Gregory P. Harhay ${ }^{4}$ and \\ Kelly M. Lager ${ }^{1}$.
}

${ }^{1}$ USDA, Agricultural Research Service, National Animal Disease Center, Virus and Prion Research Unit, 1920 Dayton Avenue, Ames, IA 50010, USA; ${ }^{2}$ Department of Animal Sciences, Washington State University, Pullman, WA 99164; ${ }^{3}$ Department of Anatomy and Physiology, College of Veterinary Medicine, Kansas State University, Manhattan, KS 66506; ${ }^{4}$ Animal Health Research Unit, United States Meat Animal Research CenterUSDA-ARS, Clay Center, Nebraska 68933

*Co-Corresponding authors. Mailing Addresses: USDA, ARS, National Animal Disease Center, P.O. Box 70, Ames, Iowa 50010-0070; Phone: 515-337-6794, E-mail: laura.miller@ars.usda.gov (L.M.). Department of Animal Sciences, Washington State University, Pullman, WA 99164; Pullman WA 99164-6351; Phone: 509-335-8761, Email: jiangz@wsu.edu (Z.J.); Department of Anatomy and Physiology, College of Veterinary Medicine, Kansas State University, Manhattan, KS 66506; Phone: 785-5324540, E-mail: ysang@vet.k-state.edu (Y.S.)

Running Head: IFITM Evolution in Pigs and SIV-induced member expression dynamics 


\begin{abstract}
Studies have found that a cluster of duplicated gene loci encoding the interferoninducible transmembrane proteins (IFITMs) family have antiviral activity against several viruses, including influenza A virus. The gene family has 5 and 7 members in humans and mice, respectively. Here, we confirm the current annotation of pig IFITM1, IFITM2, IFITM3, IFITM5, IFITM1L1 and IFITM1L4, manually annotated IFITM1L2, IFITM1L3, IFITM5L, IFITM3L1 and IFITM3L2, and provide expressed sequence tag (EST) and/or mRNA evidence, not contained with the NCBI Reference Sequence database (RefSeq), for the existence of IFITM6, IFITM7 and a new IFITM1-like (IFITM1LN) gene in pigs. Phylogenic analyses showed seven porcine IFITM genes with highly conserved human/mouse orthologs known to have anti-viral activity. Digital Gene Expression Tag Profiling (DGETP) of swine tracheobronchial lymph nodes (TBLN) of pigs infected with swine influenza virus (SIV), porcine pseudorabies virus, porcine reproductive and respiratory syndrome virus or porcine circovirus type 2 over 14 days post-inoculation (dpi) showed that gene expression abundance differs dramatically among pig IFITM family members, ranging from 0 to over 3,000 tags per million. In particular, SIV upregulated IFITM1 by 5.9 fold at 3 dpi. Bayesian framework further identified pig IFITM1 and IFITM3 as differentially expressed genes in the overall transcriptome analysis. In addition to being a component of protein complexes involved in homotypic adhesion, the IFITM1 is also associated with pathways related to regulation of cell proliferation and IFITM3 is involved in immune responses.
\end{abstract}


Keywords: Interferon-inducible transmembrane protein family member, IFITM,

Influenza Virus, Swine Genome 


\section{Introduction}

Domestic swine play an important role in human nutrition and economics since pork is the most consumed meat worldwide (http://www.fao.org/ag/againfo/themes/en/meat/backgr_sources.html). Moreover, pigs can harbor a number of zoonotic viruses of which influenza virus is the most important. Understanding how the pig responds to infectious disease may lead to better control of swine diseases that have a significant impact on pork production as well as human health. In addition, learning more about the pig immune response may lead to better animal models to study human disease. Viral respiratory diseases can cause dramatic losses in swine herds and are a major research focus worldwide. Recent advances in technology have enabled the efficient study of gene expression, which can be used to study the molecular pathogenesis and immunology of disease.

Innate antiviral immunity in the mammalian host is orchestrated by the interferon (IFN) system (type I, type II and type III) that plays a cardinal role in early detection and combat of invading viruses through IFN production and action. The interaction of virus and the host IFN-system potentially determines the outcome of most viral diseases (Gonzalez-Navajas et al., 2012; Katze et al., 2008). The interferon-induced transmembrane proteins (IFITMs) are a family of transmembrane proteins that respond differentially to IFN induction and viral infections. The IFITM genes are a subfamily in a larger family of transmembrane proteins called dispanins, which refers to a common twotransmembrane-helix protein structure (Sallman Almen et al., 2012); e.g., IFITM1 has been designated CD225. The current assembly of the human genome (Build 37.3) 
indicates there are five IFITM family members on chromosome 11: IFITM1, IFITM2, IFITM3, IFITM5 and IFITM10. The mouse genome has six members: IFITM1, IFITM2, IFITM3, IFITM5, IFITM6 and IFITM10 located on chromosome 7, and a putative IFITM7 located on chromosome 16. While the multifunctional properties of IFITMs involved in embryo development, cell adhesion/growth and tumor progression are well described (Siegrist et al., 2011), the antiviral activities of IFITMs have only recently been studied. IFITM proteins can confer basal resistance to several viruses and are critical for the virustatic actions of IFN (Brass et al., 2009). Mouse and human IFITM3 expression has been shown to restrict influenza A virus (IAV) replication and IFITM1 and 2 appear to be important in hampering the replication of Marburg and Ebola filoviruses (Everitt et al., 2012; Huang et al., 2011). In addition, IFITM1-3 proteins were found to prevent infection of a growing list of viruses such as HIV-1, SARS, West Nile and Dengue fever (Brass et al., 2009; Everitt et al., 2012; Huang et al., 2011; Lu et al., 2011). Phylogenic analyses show species-specific diverse gene composition and potential functional divergence of vertebrate IFITMs (Hickford et al., 2012; Huang et al., 2011; Siegrist et al., 2011). It is unknown if the duplicated members have virus-specific recognition patterns and signaling pathways.

Our goal was to investigate the regulatory mechanisms and expression patterns of porcine IFITMs. In the study reported here, multiple IFITM genes were demonstrated to be differentially expressed in tracheobronchial lymph nodes (TBLN) during the course of infection with one of four common viral respiratory pathogens: porcine reproductive and respiratory syndrome virus (PRRSV), swine influenza virus (SIV), porcine circovirus 
type 2 (PCV2), and pseudorabies virus (PRV). Additional analyses demonstrated how many putative porcine IFTM family members exist and which are highly conserved human/mouse orthologs that may exert anti-viral activity.

\section{Materials and Methods}

\subsection{Manual annotation and bioinformatic analyses of porcine IFITM family.}

Porcine IFITM entries were extracted from the NCBI gene database

(http://www.ncbi.nlm.nih.gov/gene/) and further curated using BLASTP against the current swine genome assembly (Sscrofa10.2) (Groenen et al., 2012). The domain structures of IFITM proteins were defined based on human IFITM entries in the Conserved Domain Database (Marchler-Bauer et al., 2013). The sequence alignment and conserved residues were analyzed with Jalview (Waterhouse et al., 2009), and the

phylogenic analysis was performed with Mega5 (Tamura et al., 2011). The subcellular location of eukaryotic proteins was predicted using a hybrid approach (Hslpred, http://www.imtech.res.in/raghava/hslpred/) and the algorithms were based on single/multiple sites (Euk-mPloc (Chou and Shen, 2010)) or a decision tree of several support vector machines (MemLoci (Pierleoni et al., 2011)).

\subsection{Virus, Animals and Experimental Design}

TBLN were collected from pigs that were part of 2 studies of virtually identical design conducted at the National Animal Disease Center (NADC), USDA, ARS, Ames, Iowa. Each study was designed to investigate the comparative global TBLN transcriptome profile of pigs infected with either PRV (Study 1), or SIV, PRRSV, or PCV2 (Study 2). 
The experimental design was similar for both studies and TBLN tissue was selected for study because the lymph from the lungs passes through these lymph nodes making them an active site in the immune response against pulmonary disease.

Prior to virus challenge at 4-5 weeks of age, pigs were determined to be free of PRV, SIV, PCV2, and PRRSV. On 0 days-post-inoculation (dpi) pigs received an intranasal challenge with $2 \mathrm{ml}$ of either challenge virus or sham inoculum (control) prepared from the respective cell culture used to propagate challenge viruses. Each group consisted of 20 pigs and was housed in an BSL-2 isolation room from 0-14 dpi, the duration of the experiment. Five pigs from each group both infected and uninfected were euthanized and necropsied on 1, 3, 6 and 14 dpi and TBLN from each pig was collected immediately, minced and stored in RNAlater (Life Technologies Corporation, Grand Island, NY) at $80^{\circ} \mathrm{C}$ until homogenized for RNA extraction.

Challenge viruses were low passage field isolates used previously at the NADC administered at about $1 \times 10^{5} \mathrm{TCID}_{50}$ per pig: PRRSV (SDSU73)(Brockmeier et al., 2012), PCV2 (Group 2 European-like)(Lager et al., 2007); SIV (A/SW/OH/511445/2007

H1N1)(Vincent et al., 2009), and PRV (FS268) (Miller et al., 2010).

\subsection{Total RNA isolation}

TBLN were thawed for homogenization to extract total RNA with MagMAX ${ }^{\mathrm{TM}}-96$ for Microarrays Total RNA Isolation Kit (Applied Biosystems, Carlsbad, CA) using the manufacturer's protocol. The integrity of the RNA was confirmed with a 2100 
Bioanalyzer and RNA 6000 Nano-chip (Agilent, Santa Clara, CA). The samples used had an average RNA integrity number (RIN) value of 7.8 and 28S:18S rRNA ratio of 1.9. In transcriptome sequencing protocols, it is always advised to use high quality RNA of RIN $>7$.

\subsection{Digital Gene Expression Tag Profiling}

For each necropsy time point, total RNA was pooled for each group to make cDNA libraries for analysis by digital gene expression tag profiling (DGETP). DGETP uses the restriction enzyme, DpnII, to cut $21 \mathrm{bp}$ long sequence tags from each transcript's cDNA, thus expanding the tag-size by at least $7 \mathrm{bp}$ as compared to the predecessor techniques of serial analysis of gene expression (SAGE) and LongSAGE. The longer tag-size allows for a more precise allocation of the tag to the corresponding transcript, because each additional base increases the confidence in the mapping of the tag to a transcript or genomic position.

Tag library preparation was performed at the Iowa State University DNA facility using a DGE-Tag Profiling DpnII Sample Prep kit and protocol (Illumina, Hayward, CA). In brief, total RNA aliquots ( 1 or $2 \mu \mathrm{g}$ ) were diluted in $50 \mu \mathrm{L}$ of nuclease-free $\mathrm{H}_{2} \mathrm{O}$ and heated at $65^{\circ} \mathrm{C}$ for $5 \mathrm{~min}$ to disrupt secondary structure prior to incubation with magnetic oligo-dT beads to capture the poly-adenlyated RNA fraction. First and second-strand cDNA was synthesized and bead-bound cDNA was subsequently digested with DpnII to

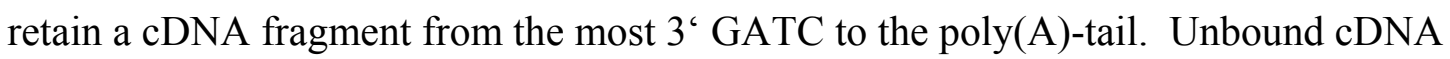
fragments were washed away prior to ligation with the GEX DpnII adapter to the 5' end 
of the bead-bound digested cDNA fragments. This adapter contains a restriction site for MmeI which cuts 17 bp downstream from the DpnII site. After subsequent digestion with MmeI, 21 bp tags starting with the DpnII recognition sequence were recovered from the beads and dephosphorylated prior to phenol/chloroform extraction. Then, a second adapter (GEX adapter 2) was ligated onto the 3' end of the cDNA tag at the MmeI cleavage site. The adapter-ligated cDNA tags were enriched by a 15-cycle PCR amplification using Phusion DNA polymerase (Finnzymes Oy, Illumina-supplied, Hayward, CA) and primers complementary to the adapter sequences. The resulting fragments were purified by excision from a $6 \%$ polyacrylamide Tris/Borate/EDTA (TBE) gel.

The DNA was eluted from the gel debris with $1 \times$ NEBuffer 2 by gentle rotation for $2 \mathrm{~h}$ at room temperature. Gel debris were removed using Spin-X Cellulose Acetate Filter ( $2 \mathrm{ml}$, $0.45 \mu \mathrm{m})$ and the DNA was precipitated by adding $10 \mu \mathrm{l}$ of $3 \mathrm{M}$ sodium acetate ( $\mathrm{pH} 5.2)$ and $325 \mu \mathrm{l}$ of ethanol $\left(-20^{\circ} \mathrm{C}\right)$, followed by centrifugation at $14,000 \times \mathrm{g}$ for $20 \mathrm{~min}$. After washing the pellet with $70 \%$ ethanol, the DNA was resuspended in $10 \mu 1$ of $10 \mathrm{mM}$ Tris$\mathrm{HCl}$, pH8.5 and quantified with a Nanodrop 1000 spectrophotometer. Sequencing using Solexa/Illumina Whole Genome SequencerCluster generation was performed after applying $4 \mathrm{pM}$ of each sample to the individual lanes of an Illumina $1 \mathrm{G}$ flowcell. After hybridization of the sequencing primer to the single-stranded products, 18 cycles of base incorporation were carried out on the $1 \mathrm{G}$ analyzer according to the manufacturer's instructions. Image analysis and basecalling were performed using the Illumina Pipeline, where sequence tags were obtained after purity filtering. 


\subsection{Transcriptome determination}

First, 64,100 pig mRNA sequences were downloaded from the GenBank database. A Java program was developed to identify the 3' most DpnII cut site, followed by collection of the DGETP tags of 16 nucleotides for each mRNA. By excluding genes/transcripts that had no enzyme cut site and that were potentially repeated entries, we compiled a list of 29,599 genes/transcripts with one tag sequence collected. Second, the unique gene/transcript tags were then used as references to filter each library. Combining the data from the libraries (infected and control) described above revealed that of 29,599 genes/transcripts, 21,144 genes/transcripts were expressed. Third, we used a Bayesian framework approach(Jiang et al., 2013) and determined a total of 1,503 differentially expressed (DE) genes/transcripts among these libraries described above, which were then annotated for orthologs in the human genome against the Refseq database, as the human genome has been well annotated. Lastly, these DE genes were assigned to their associated pathways using the DAVID database (Huang da et al., 2007).

\subsection{Quantitative real-time PCR (Q-PCR) analysis}

Validation of the results and corroboration of the altered transcript abundance levels were analyzed by real-time reverse transcription-PCR (RT-PCR) on the individual sample of $100 \mathrm{ng}$ total RNA from each pig at each time point. Real-time RT-PCR was done in $25 \mu 1$ reaction volumes using the SuperScript III Platinum SYBR green One Step qRT-PCR kit (Invitrogen, Carlsbad, CA) according to the supplier's specifications. The IFITM primer sets used for this analysis are shown in Table 1. IFN- $\alpha_{1}$ (Ss03394862_g1) and IFN- $\beta$ 
(Ss03378485_u1) primers were purchased as Taqman ${ }^{\circledR}$ Custom Probe/Primer sets from Applied Biosystems (Carlsbad, CA). All primers were used at 200 nM. PCR cycling conditions were $50^{\circ} \mathrm{C}$ for 3 minutes, $95^{\circ} \mathrm{C}$ for 5 minutes followed by 40 cycles of $95^{\circ} \mathrm{C}$ for 15 seconds, $60^{\circ} \mathrm{C}$ for 1 minute, and then, for dissociation curve analysis: $95^{\circ} \mathrm{C}$ for 15 seconds, $60^{\circ} \mathrm{C}$ for 15 seconds and $95^{\circ} \mathrm{C}$ for 15 seconds using an fluorescent thermocycler 7900 (Applied Biosystems, Carlsbad, CA). For real-time PCR, 18S served as the internal control. Relative transcript abundance levels for the other genes were calculated by the $2^{-}$ ${ }^{\Delta \Delta \mathrm{CT}}$ method (Livak and Schmittgen, 2001).

\section{Results and Discussion}

\subsection{Structural conservation of pig IFITM family genes}

The current assembly of the pig genome (Build 10.2) indicates the presence of 12 potentially functional gene loci in the IFITM family (IFITM1, IFITM2, IFITM3, IFITM1L1, IFITM1L2, IFITM1L3, IFITM1L4, IFITM5, IFITM5L, IFITM3L1, IFITM3L2 and IFITM10), while humans and mice possess only 5 (IFITM1, IFITM2, IFITM3, IFITM5 and IFITM10) and 7 (IFITM1, IFITM2, IFITM3, IFITM5, IFITM6, IFITM7 and IFITM10) members, respectively (Figure 1). These loci were manually annotated for validation and to comparatively discover all other IFITM family members in pigs using expressed sequence tags (ESTs) and non RefSeq RNA resources, i.e. those outside of the limits of the curated RefSeq database of 21,415 distinct "named" organisms (ftp://ftp.ncbi.nlm.nih.gov/refseq/release/) such as DDBJ/EMBL/GenBank the primary sequence archive, as evidence. The current draft pig genome assembly has 11 IFITM family members located on chromosome 2 , and 1 member on chromosome 1 . The 
annotated gene loci, gene symbols, chromosome coordinates, model RefSeq accession numbers and their genomic structures and elements for those porcine IFITM family members with EST evidence are detailed in Table 1.

These data raise two questions: 1) how many pig IFITM family members would be confirmed with ESTs and/or non RefSeq RNA support as evidence and 2) what is the fate for both IFITM6 and IFITM7 in the pig genome as they are not found in the human genome, but are in the mouse genome? BLAST searches using the model RefSeq sequences of pig IFITM family members against both pig EST and non RefSeq RNA databases confirmed the annotation of pig IFITM1 (XM_003124230.1), IFITM2 (NM_001246214.1), IFITM3 (NM_001201382.1), IFITM5 (XM_003124229.3), IFITM1L1 (XM_003354415.1) and IFITM1L4 (XM_003124235.2) (Table 2 and Figure 2). The deduced amino acid sequences indicated two annotated loci (IFITM1L2, XM_003354408.1/XM_003354411.1 nd IFITM5L,XM_003354416.2) might be annotated duplications as they had the same protein sequences to XM_003354415.1 and XM_003124229.3 (Figure 2). At least three ESTs (HX217039, HX212553 and HX213228) provided evidence for existence of IFITM6 and one EST (AJ648852) for IFITM7 in pigs. Several non RefSeq RNA entries (AK234776, AK396508 and AK348267) also supported a new IFITM1-like gene (IFITM1LN) in the species (Figure 2). However, we did not find any ESTs and/or non RefSeq RNA to support the model RefSeqs for LOC100621926 (XM_003353647.2), LOC100627740 (XM_003354422.2) and LOC100627649 (XM_003354421.1) (Table 2). The continuous gene locus of porcine IFITM2 was not defined, but the 5'- and 3'-parts of its transcripts (see Fig. 2 for 
the ESTs containing the full-length of IFITM2 coding region) were detected and found to be identical to exon 1 of IFITM3 and exon 2 of IFITM1 (or IFITM1L4), respectively. We have isolated IFITM2 cDNA clones from alveolar macrophages that show diverse 3'regions identical to exons 2 of IFITM1, IFITM1L2 or IFITM1L4 genes, respectively, (data not shown). Therefore, there are multiple porcine IFITM2 variants originating through alternative splicing or exon shuffling. In addition, sequence on an unplaced genomic scaffold (NW_003541064.1, Sscrofa10.2) was found to have 100\% identity to the N-terminal $\sim 160$ nt of human IFITM10 (Fig. 1), but no EST evidence was detected for porcine IFITM10.

Our annotation and validation revealed that eight members of pig IFITM family have partial or entire genomic DNA sequences available in two contigs: CU928488.2 and FP565362.1. These members all have a conserved genomic organization: two exons and one intron (Figure 2). The intron regions are completely sequenced for IFITM1, IFITM3, IFITM5, IFITM1L1 and IFITM1L4, and partially sequenced for IFITM6 and IFITM1LN. There are two forms of 3'UTR regions: a long 3'UTR over $1 \mathrm{~kb}$ in length and a short 3'UTR less than $250 \mathrm{bp}$ in length. The putative core promoter regions of the porcine IFITM genes, except two IFITM5-like isoforms, are predicted to contain interferon stimulated response elements (ISRE) (Figure 1 and Table 2).

Although their current nomenclatures are arguable, these members encode proteins that are relatively different in $\mathrm{N}$ - and $\mathrm{C}$-terminus regions compared with a highly conserved CD225 superfamily domain that includes one or two transmembrane regions (Figure 3A). 
Except for IFITM5 and the tentative IFITM7, other porcine IFITM proteins appear to be combinations with different types of $\mathrm{N}$-terminus regions and $\mathrm{C}$-terminus regions (Figure 2). Phylogenic analysis of all IFITMs from humans, mice and pigs shows that IFITM5 orthologs from the three species form a separate cluster, whereas all other IFITMs have evolved from a common ancestor undergoing gene duplication and conversion in each species (Figure 3B) (Hickford et al., 2012; Sallman Almen et al., 2012; Siegrist et al., 2011). Because human IFITM1-3 and mouse IFITM3 isoforms have been found to restrict influenza virus replication and infection (Brass et al., 2009; Everitt et al., 2012; Huang et al., 2011), we predict that pigs may have as many as seven IFITMs (IFITM1, 1L1, 1L2, 1L3, 1L4, 2 and 3) within the IFITM1-3 cluster (Figure 3B) that potentially exert anti-influenza activity apart from two (CD225-truncated IFITM3L1 and 3L2) that are functionally unknown "mutants". Generally grouped as IFITMs, the subcellular localization and membrane integration of IFITMs are dynamically regulated by posttranslational modifications (PTMs) involving addition of hydrophobic groups for membrane localization (Mann and Jensen, 2003). These PTMs, including myristoylation, palmitoylation and prenylation, could be critical in the regulation of IFITM antiviral activity as shown for the S-palmitoylation of human IFITM3 (Yount et al., 2010). We have identified the predicted conserved cysteine and glycine residues in porcine IFITMs (Figure 3A), which are potentially involved in the PTMs for regulation of IFITM membrane localization and antiviral activity. We applied three programs for predicting the subcellular location of eukaryotic proteins using a hybrid approach (Hslpred, http://www.imtech.res.in/raghava/hslpred/), the algorithms were based on single/multiple sites (Euk-mPloc (Chou and Shen, 2010)), and a decision tree of several support vector 
machines (MemLoci (Pierleoni et al., 2011)). These programs consistently predicted that IFITM5 orthologs are cytoplasmic proteins, while most human or porcine IFITM1-3 isoforms appear to be localized in cytoplasm, cell membrane, mitochondria or secreted into extracellular spaces (Table 3). We conclude that antiviral IFITMs should be dynamically regulated through PTMs for their correct sub-cellular location to exert biological, including antiviral, function.

\subsection{Clinical evaluation}

A comparative study of four swine viral respiratory diseases was completed to evaluate if transcriptome changes in TBLNs were virus-specific, or if they reflected a common response to viral pneumonia regardless of the viral pathogen. PRRSV, PRV, and PCV2 produce a systemic infection in contrast to SIV that primarily infects epithelial tissues in the respiratory tract. However, each virus is capable of replicating in the lung and causing disease therein, the magnitude of which can be dependent on many factors including the viral isolate used. Each virus challenge induced a respiratory disease that resembled what was expected based on experimental and natural infections (as reviewed in (Straw, 1999). Briefly, SIV induced a mild acute clinical disease most apparent between 1 and 3 dpi that was resolving by 14 dpi. The onset of moderate clinical disease in PRRSV- and PRV-infected pigs began 3-6 dpi and was maximal at 14 dpi with some animals beginning convalescence by $14 \mathrm{dpi}$. In contrast, minimal to no clinical disease or lesions were recognized in PCV2-infected pigs during the experiment. Based on clinical signs, the respiratory disease observed in this study can be separated into an acute response that was resolving by 6 dpi (SIV), a slightly delayed response that developed 
maximum lesions by 6 and 14 dpi (PRV and PRRSV) (Brockmeier et al., 2002), and a delayed/minimal response throughout each time-point in the PCV2-infected pigs. In general, for each treatment group a direct relationship was found between virus load and magnitude of disease. For example, in the case of SIV-infected pigs the detection of replicating challenge virus peaked quickly and the pigs had almost cleared the virus by 6 dpi and were negative by $14 \mathrm{dpi}$. In contrast, the PCV2-infected pigs developed a relatively small virus load throughout the experiment.

\subsection{Expression dynamics of pig IFITM family genes}

We used TPM (tags per million) values to show basic expression features of pig IFITM family members in TBLN of pigs infected with SIV. In addition to SIV, our experiment also involved PRV, PCV2, and PRRSV, plus sham-inoculated controls for comparison. In brief, we made a total of 24 DGETP libraries, including 16 derived from four virus challenges and 8 samples from two sets of control at 1, 3,6 and 14 dpi. Due to sequence similarity, we found that IFITM1LN and IFITM2, IFITM1L4 and IFITM1LN, IFITM3 and IFITM1L1 shared the 3' most DpnII cut tags: TTTTGAAAAAAAAAAA, TTTTGATGTTGAAAAA and AACATCCGAAGCGAGA, respectively. However, an allelic tag (TTTTAAAAAAAAAAAA) was identified for IFITM2, while unique tags (CTGGGCCTCATTCTGA, AGAAGGTGGCTGGAGA and ACCATCCCCAGGGAGA) were found for IFITM1, IFITM5 and IFITM6, respectively. As the tentative IFITM7 has an incomplete cDNA sequence, we excluded it in the analysis. These tag sequences can be found in the mRNA sequences listed in Figure 2. The validity and kinetics of transcript abundance of IFITM1, IFITM1L1, IFITM1L2, 
IFITM1L3, IFITM1L4, IFITM2, IFITM3, IFITM3L1, IFITM3L2 and IFITM5 were evaluated using real-time RT-PCR (Fig. 5). Regardless of the member ambiguities caused by sequence similarity between IFITM members in Figure 4, the expression dynamics of IFITM1, IFITM2, IFITM3, IFITM1L1 and IFITM1L4 were similarly examined using both DGETP and RT-PCR, and were found to be consistent, particularly in the tissues infected with SIV, PRV and PCV2. However, the expression dynamics of IFITM family members in PRRSV-infected tissues showed different profiles between the two quantitative techniques, i.e. earlier stimulation in DGETP in contrast to the latter stimulation in the RT-PCR assays. This may require further investigation.

The abundance of gene expression in the present study is quite different among the pig IFITM family members regardless of virus. As shown in Figure 4 in the DGETP data, IFITM2, IFITM1L4, IFITM1LN and IFITM6 seem abundantly expressed, but none expressed more than 400 TPM per library. However, expression of IFITM1 and IFITM3/IFITM1L1 increased in response to infection dramatically, with instances reaching over 3,000 TPM per sample (Figure 4). We also noted that the relative abundance of gene expression detected was quite different among the DGETP and RTPCR data (Figure 4 and 5) as seen in other studies the DGETP method often produced higher transcript ratios (in either direction) than real-time quantitative RT-PCR (David et al., 2010). (Liu et al., 2011) also observed a systematic bias for RNA-Seq in the analysis of genes with relatively low expression levels. Specifically, DEGs missed by RNA-Seq (i.e. false negatives) were characterized by low expression levels in the examined samples, as indicated by lower RNA-Seq read counts and higher raw $\mathrm{C}_{t}$ values by real- 
time qPCR. While the expression levels of IFITM1 and IFITM3/IFITM1L1 had 10-100 fold higher expression than others in the DGETP data (Figure 4), the gene-specific RTPCR analysis showed more uniform expression abundance among different IFITM members, except IFITM2 that had the highest expression particularly at 3 dpi of PRV infection. Considering that the DGETP analyses probably assigned multiple IFITM1-like (including IFITM1 and IFITM1L1-1L4) and IFITM3-like (including IFITM3 and IFITM3L1-3L2) homologs under IFITM1 and IFITM3, the higher abundance of IFITM1 and IFITM3 in DGETP data was understandable. In addition, IFITM5 was expressed at low levels in porcine TBLN, as the DGETP analysis TPM ranged from 0 to 1.2 in both virus-challenged samples and controls and in RT-PCR there was no noticeable fold change from control in the virus-infected samples. As shown in Table 2, IFITM5 does not contain an interferon stimulated response element (ISRE) in its promoter region indicating the gene is not interferon inducible. Therefore, it does not surprise us that expression of the pig IFITM5 was not induced by virus.

Gene expression response timing depends on the type of virus. As illustrated in Figure 4, the IFITM family members responded to SIV infection relatively slowly, as their upregulated peaks appear at 3 dpi (five out of six instances). However, in the TBLN of pigs infected with PRV, PCV2 or PRRSV, the IFITM family members responsed more quickly and peaked at $1 \mathrm{dpi}$ (four, six and five out of six instances for PRV, PCV2 and PRRSV, respectively). It is interesting that although the IFITM family transcriptome profile was repressed in response to SIV compared to the other viruses (with the possible exception of IFITM1), SIV was the only virus cleared by the pigs over the 14-day 
duration of the experiment. The comparatively lower and slower up-regulation of most porcine IFITM genes in response to SIV infection as compared to the response to the other viruses may imply IFITMs were particularly targeted for suppression by SIV, indicating a rational feasibility for combating SIV through timely stimulation of porcine IFITM expression.

The ability of a virus to up-regulate the gene family differed. For each chart in Figure 4, we include the expression mean and its $95 \%$ confidence interval in the controls for each tag. PRV elicited the highest transcription levels, while PCV2 shows the weakest transcriptional activation by the IFITM family. Among a total of 24 instances $(6$ tags $x 4$ time-points), the PRV caused 9 instances of up-regulation by over 4-fold, while PCV2 produced a single instance with over 4-fold up-regulation. PRRSV also strongly stimulated high expression of the gene family, but the gene family reacted to SIV in a comparatively mild manner (Figure 4). However, SIV up-regulated IFITM1 by 5.9 fold at day 3 post infection, the second highest to 6.5 fold at the same time-point with PRRSV infection.

Our current research revealed a limitation associated with the DGETP-based RNA-seq method, i.e., one tag can represent different genes/transcripts, particularly when gene family members have highly similar sequences. Our understanding is that RNA-seq cannot solve this problem either. The Illumina sequencing techniques usually produce sequences with a maximum of $100 \mathrm{bp}$ in length. The highly conserved protein sequences shown in Figure 2 for several members of pig IFITM family are actually encoded by the 
highly similar RNA molecules. As such, the same piece of the sequence provided by RNA-seq cannot be unequivocally assigned to any individual member in the gene family. In addition, the major drawbacks of whole transcriptome shotgun sequencing or RNA-seq include insufficient detection of genes/transcripts with low levels of expression, uneven sequencing depth along the length of a transcript and impossible usage of spreadsheet software for data processing due to large file size, (as reviewed by (Malone and Oliver, 2011). Our solution was to use different enzyme combinations and then identify a signature tag specifically for each member. For example, we found that a combination of four enzymes: Tsp509I (AATT), NlaIII (CATG), MspI (CCGG) and DpnII (GATC) covered $99.64 \%$ of the Sus scrofa transcriptome.

\subsection{Differentially expressed TBLN transcriptomes of pigs infected with SIV: an overview}

Overall, we used a Bayesian framework approach and determined a total of 1,503 differentially expressed (DE) genes/transcripts in TBLN of pigs infected with SIV in the present study. Annotation of these DE genes/transcripts, based on their orthologous human counterparts, revealed a list of 1,286 functionally known genes. DAVID assigned 1,221 of them to 403 functional clusters. The top ten enriched functional clusters included genes associated with lysosomes (enrichment Score: 9.89), membrane-bounded vesicles (enrichment Score: 8.32), isopeptide bonds (enrichment Score: 6.10), apoptosis (enrichment Score: 5.95), regulation of apoptosis (enrichment Score: 5.71), inflammatory response (enrichment Score: 5.32), protein transport (Enrichment Score: 4.51), RNA binding and processing (enrichment Score: 4.28), protein biosynthesis (enrichment Score: 4.25) and the nucleoplasm (enrichment Score: 3.97). 
Among the pig IFITM family members, only IFITM1 and IFITM3 were identified as DE genes in TBLN of pigs infected with SIV. Both members are involved in gene clusters as integral to membrane. In addition, IFITM1 is also associated with the regulation of cell proliferation pathways involving 89 genes identified in the present study: NAMPT, NBN, AIF1, OSMR, TSG101, STAT5A, IL18, BTC, PPARG, NAP1L1, BAP1, SKAP2, TGFB1, CXCL10, S1PR2, MAGED1, MEN1, GPX1, CDCA7, GPC3, NDUFS4, CDKN2D, HMOX1, ILK, SERPINE1, SHC1, PDGFC, LTB, AKIRIN2, AGPAT1, MAP2K5, CTBP1, ARHGEF2, RBBP4, LYN, CD164, PPP1CB, MAPK1, TNS3, CD38, HHEX, BTG1, CD33, GRN, VEGFA, PDGFRB, ADAM17, EMP3, VSIG4, CNBP, CAV1, CCL2, LST1, IFITM1, GNAI2, PML, COMT, TIMP2, FTH1, CDH5, TIMP1, CD9, TSPAN31, CDC123, CAMK2D, TGM2, THBS1, LAMB1, PPAP2A, CD5, TXNIP, PTPRC, BECN1, PHB, ANXA1, DUSP22, SKI, IGF2, STAT1, CAPN1, CDC25B, PLA2G4A, CDKN1B, CCL14, HDAC1, FABP3, FABP4, HGS and ENG.

IFITM3 was assigned to an immune response pathway associated with 91 genes: NBN, IL27RA, IL16, IL18, PPARG, TLR1, TIRAP, PRDX2, TLR4, NFKB2, LY9, CXCL12, PRDX1, C1QC, TGFB1, CXCL10, CFP, LTB, FCGR3B, AKIRIN2, LAIR1, C5AR1, SIT1, BST2, LYN, LY96, SLA2, CNPY3, HLA-A, SERPING1, CD164, SIGIRR, C1QB, VEGFA, ADAM17, CTSC, MADCAM1, SEMA4D, VSIG4, LCP1, GBP1, YWHAZ, CCL2, LST1, HLA-DRB1, C3, IFITM3, TFE3, CXCL9, ACP5, CALCOCO2, OAS1, FCGRT, C1S, OAS2, FTH1, CCL26, SQSTM1, FCN1, FCER1G, C2, THBS1, DHX58, ARHGDIB, FYB, MSH6, PTPRC, ST6GAL1, CR2, SWAP70, CFB, SAMHD1, 
CCL19, C4BPA, PSMB8, CD1D, CYBA, GPI, LAT, OASL, TNFSF10, CCL14, RGS1, FCGR2B, CXCL14, CXCL13, CD209, ANXA11, HSPD1, CD14 and IFI6.

As indicated above, IFITM family members responded to SIV, PRV, PCV2 and PRRSV differently. IAV belongs to the family of Orthomyxoviridae viruses. The pig is a natural host and a "mixing vessel" for IAV cross-species transmission particularly to humans (Ma et al., 2008; Vincent et al., 2008). Critically, influenza in pigs resembles influenza in humans: i) The same influenza A subtypes ( $\mathrm{H} 1$ and $\mathrm{H} 3)$ are predominately circulating and many are capable of causing disease in both human and swine populations; ii) Infected pigs display similar clinical symptoms as found in humans, such as fever, coughing, lethargy, anorexia and nasal discharge; iii) both species have a similar viral clearance phase of around 7-10 days. Therefore, the pig is a good mammalian model to study zoonotic influenza A virus (Kuiken et al., 2011; Ma and Richt, 2010; Torremorell et al., 2012). Although vaccines against influenza are available for humans and farm animals, it remains a challenge to control outbreaks of influenza infections because the virus evolves rapidly to evade host immunity through antigenic drift and shift. IFITMs are a group of transmembrane proteins that respond differentially to IFN induction and viral infections. Figure 6 shows the IFN- $\alpha_{1}$ and IFN- $\beta$ transcript abundance elevated at 3 dpi for PRRSV and PCV-2 (IFN- $\alpha_{1}$ only), and at 1 and 14 dpi for IFN- $\beta$ for PRV, as measured by RT-PCR in the TBLN of the infected pigs compared to controls. This IFN transcript data agrees with previous findings of a delayed or inhibited IFN response in PRRSV infection (Albina et al., 1998; Lee et al., 2004; Loving et al., 2007; Miller et al., 2004; Van Reeth et al., 1999). In the case of influenza A virus, the viral non-structural 
protein 1 (NS1) has been described to act as a powerful antagonist of IFN induction (Hale et al., 2008) and this may explain why IFN- $\alpha / \beta$ transcript abundance was not elevated in the TBLN of the SIV-infected pigs. Alternatively, it is possible we do not detect high levels in the TBLN of SIV-infected pigs because induction of IFN- $\alpha / \beta$ usually occurs with $2 \mathrm{hr}$ post-infection (Solorzano et al., 2005) and the peak transcript abundance may have been missed at our 1dpi time-point. Our data highlights that porcine IFITMs, the family of early response IFN-stimulated genes (ISGs) are part of the pig's antiviral response against influenza (Brass et al., 2009; Everitt et al., 2012; Huang et al., 2011).

This report presents the first description of the TBLN transcriptome responses of porcine IFITM and the genomic organization of the IFITMs in relation to the mouse and human genomes. These data indicate a need for more extensive transcriptional and functional characterization of porcine IFITMs, which will further our understanding of the IAV-host interaction and discovery of the host defense potential of IFITMs against pandemic SIV infection. 


\section{Acknowledgements}

This work was supported in part by the National Pork Board Grant \#08-247, the United States Department of Agriculture (USDA) Agricultural Research Service, and the Porcine Reproductive and Respiratory Syndrome Coordinated Agricultural Project USDA National Institute of Food and Agriculture Award 2008-55620-19132. We thank the following members of the Virus and Prion Research Unit at the National Animal Disease Center: A. Vincent, K. Faaberg and A.Cheung for providing the virus stock; J. Huegel and B. Pottenbaum for animal caretaking; and M. Baker (Iowa State University) M. Harland, D. Adolphson, S. Anderson, E. Zanella and A. Vorwald for technical assistance. Mention of trade names or commercial products in this article is solely for the purpose of providing specific information and does not imply recommendation or endorsement by the U.S. Department of Agriculture. USDA is an equal opportunity provider and employer.

\section{Conflict of Interest}

The authors have declared that no conflict of interest exists.

\section{Ethics}

The animal studies were reviewed and approved by the Institutional Animal Care and Use Committee (IACUC) of the National Animal Disease Center-USDA-Agricultural Research Service. 


\section{References}

Albina, E., Carrat, C., Charley, B., 1998. Interferon-alpha response to swine arterivirus (PoAV), the porcine reproductive and respiratory syndrome virus. J Interferon Cytokine Res 18, 485-490.

Brass, A.L., Huang, I.C., Benita, Y., John, S.P., Krishnan, M.N., Feeley, E.M., Ryan, B.J., Weyer, J.L., van der Weyden, L., Fikrig, E., Adams, D.J., Xavier, R.J., Farzan, M., Elledge, S.J., 2009. The IFITM proteins mediate cellular resistance to influenza A H1N1 virus, West Nile virus, and dengue virus. Cell 139, 1243-1254.

Brockmeier, S., Halbur, P., Thacker, E., 2002. Porcine Respiratory Disease Complex, in: KA, B., JM, G. (Eds.), Polymicrobial Diseases. ASM Press, Washington (DC).

Brockmeier, S.L., Loving, C.L., Vorwald, A.C., Kehrli, M.E., Jr., Baker, R.B., Nicholson, T.L., Lager, K.M., Miller, L.C., Faaberg, K.S., 2012. Genomic sequence and virulence comparison of four Type 2 porcine reproductive and respiratory syndrome virus strains. Virus Res 169, 212-221.

Chou, K.C., Shen, H.B., 2010. A new method for predicting the subcellular localization of eukaryotic proteins with both single and multiple sites: Euk-mPLoc 2.0. PLoS One 5, e9931.

David, J.P., Coissac, E., Melodelima, C., Poupardin, R., Riaz, M.A., Chandor-Proust, A., Reynaud, S., 2010. Transcriptome response to pollutants and insecticides in the dengue vector Aedes aegypti using next-generation sequencing technology. BMC Genomics 11, 216.

Everitt, A.R., Clare, S., Pertel, T., John, S.P., Wash, R.S., Smith, S.E., Chin, C.R., Feeley, E.M., Sims, J.S., Adams, D.J., Wise, H.M., Kane, L., Goulding, D., Digard, P., 
Anttila, V., Baillie, J.K., Walsh, T.S., Hume, D.A., Palotie, A., Xue, Y., Colonna, V., Tyler-Smith, C., Dunning, J., Gordon, S.B., Smyth, R.L., Openshaw, P.J., Dougan, G., Brass, A.L., Kellam, P., 2012. IFITM3 restricts the morbidity and mortality associated with influenza. Nature 484, 519-523.

Gonzalez-Navajas, J.M., Lee, J., David, M., Raz, E., 2012. Immunomodulatory functions of type I interferons. Nat Rev Immunol 12, 125-135.

Groenen, M.A., Archibald, A.L., Uenishi, H., Tuggle, C.K., Takeuchi, Y., Rothschild, M.F., Rogel-Gaillard, C., Park, C., Milan, D., Megens, H.J., Li, S., Larkin, D.M., Kim, H., Frantz, L.A., Caccamo, M., Ahn, H., Aken, B.L., Anselmo, A., Anthon, C., Auvil, L., Badaoui, B., Beattie, C.W., Bendixen, C., Berman, D., Blecha, F., Blomberg, J., Bolund, L., Bosse, M., Botti, S., Bujie, Z., Bystrom, M., Capitanu, B., Carvalho-Silva, D., Chardon, P., Chen, C., Cheng, R., Choi, S.H., Chow, W., Clark, R.C., Clee, C., Crooijmans, R.P., Dawson, H.D., Dehais, P., De Sapio, F., Dibbits, B., Drou, N., Du, Z.Q., Eversole, K., Fadista, J., Fairley, S., Faraut, T., Faulkner, G.J., Fowler, K.E., Fredholm, M., Fritz, E., Gilbert, J.G., Giuffra, E., Gorodkin, J., Griffin, D.K., Harrow, J.L., Hayward, A., Howe, K., Hu, Z.L., Humphray, S.J., Hunt, T., Hornshoj, H., Jeon, J.T., Jern, P., Jones, M., Jurka, J., Kanamori, H., Kapetanovic, R., Kim, J., Kim, J.H., Kim, K.W., Kim, T.H., Larson, G., Lee, K., Lee, K.T., Leggett, R., Lewin, H.A., Li, Y., Liu, W., Loveland, J.E., Lu, Y., Lunney, J.K., Ma, J., Madsen, O., Mann, K., Matthews, L., McLaren, S., Morozumi, T., Murtaugh, M.P., Narayan, J., Nguyen, D.T., Ni, P., Oh, S.J., Onteru, S., Panitz, F., Park, E.W., Park, H.S., Pascal, G., Paudel, Y., Perez-Enciso, M., Ramirez-Gonzalez, R., Reecy, J.M., Rodriguez-Zas, S., Rohrer, G.A., Rund, L., Sang, Y., Schachtschneider, K., Schraiber, J.G., Schwartz, J., Scobie, L., Scott, C., 
Searle, S., Servin, B., Southey, B.R., Sperber, G., Stadler, P., Sweedler, J.V., Tafer, H., Thomsen, B., Wali, R., Wang, J., Wang, J., White, S., Xu, X., Yerle, M., Zhang, G., Zhang, J., Zhang, J., Zhao, S., Rogers, J., Churcher, C., Schook, L.B., 2012. Analyses of pig genomes provide insight into porcine demography and evolution. Nature 491, 393398.

Hale, B.G., Randall, R.E., Ortin, J., Jackson, D., 2008. The multifunctional NS1 protein of influenza A viruses. J Gen Virol 89, 2359-2376.

Hickford, D., Frankenberg, S., Shaw, G., Renfree, M.B., 2012. Evolution of vertebrate interferon inducible transmembrane proteins. BMC Genomics 13, 155.

Huang da, W., Sherman, B.T., Tan, Q., Collins, J.R., Alvord, W.G., Roayaei, J., Stephens, R., Baseler, M.W., Lane, H.C., Lempicki, R.A., 2007. The DAVID Gene Functional Classification Tool: a novel biological module-centric algorithm to functionally analyze large gene lists. Genome biology 8, R183.

Huang, I.C., Bailey, C.C., Weyer, J.L., Radoshitzky, S.R., Becker, M.M., Chiang, J.J., Brass, A.L., Ahmed, A.A., Chi, X., Dong, L., Longobardi, L.E., Boltz, D., Kuhn, J.H., Elledge, S.J., Bavari, S., Denison, M.R., Choe, H., Farzan, M., 2011. Distinct patterns of IFITM-mediated restriction of filoviruses, SARS coronavirus, and influenza A virus. PLoS Pathog 7, e1001258. Jiang, Z., Zhou, X., Michal, J.J., Wu, X.L., Zhang, L., Zhang, M., Ding, B., Liu, B., Manoranjan, V.S., Neill, J.D., Harhay, G.P., Kehrli, M.E., Jr., Miller, L.C., 2013. Reactomes of porcine alveolar macrophages infected with porcine reproductive and respiratory syndrome virus. PLoS One 8, e59229. 
Katze, M.G., Fornek, J.L., Palermo, R.E., Walters, K.A., Korth, M.J., 2008. Innate immune modulation by RNA viruses: emerging insights from functional genomics. Nat Rev Immunol 8, 644-654.

Kuiken, T., Fouchier, R., Rimmelzwaan, G., van den Brand, J., van Riel, D., Osterhaus, A., 2011. Pigs, poultry, and pandemic influenza: how zoonotic pathogens threaten human health. Advances in experimental medicine and biology 719, 59-66.

Lager, K.M., Gauger, P.C., Vincent, A.L., Opriessnig, T., Kehrli, M.E., Jr., Cheung, A.K., 2007. Mortality in pigs given porcine circovirus type 2 subgroup 1 and 2 viruses derived from DNA clones. Vet Rec 161, 428-429.

Lee, S.M., Schommer, S.K., Kleiboeker, S.B., 2004. Porcine reproductive and respiratory syndrome virus field isolates differ in in vitro interferon phenotypes. Vet Immunol Immunopathol 102, 217-231.

Liu, S., Lin, L., Jiang, P., Wang, D., Xing, Y., 2011. A comparison of RNA-Seq and high-density exon array for detecting differential gene expression between closely related species. Nucleic Acids Res 39, 578-588.

Livak, K.J., Schmittgen, T.D., 2001. Analysis of relative gene expression data using realtime quantitative PCR and the 2(-Delta Delta C(T)) Method. Methods 25, 402-408. Loving, C.L., Brockmeier, S.L., Sacco, R.E., 2007. Differential type I interferon activation and susceptibility of dendritic cell populations to porcine arterivirus. Immunology 120, 217-229.

Lu, J., Pan, Q., Rong, L., He, W., Liu, S.L., Liang, C., 2011. The IFITM proteins inhibit HIV-1 infection. Journal of virology 85, 2126-2137. 
Ma, W., Kahn, R.E., Richt, J.A., 2008. The pig as a mixing vessel for influenza viruses: Human and veterinary implications. J Mol Genet Med 3, 158-166.

Ma, W., Richt, J.A., 2010. Swine influenza vaccines: current status and future perspectives. Anim Health Res Rev 11, 81-96.

Malone, J.H., Oliver, B., 2011. Microarrays, deep sequencing and the true measure of the transcriptome. BMC biology 9, 34 .

Mann, M., Jensen, O.N., 2003. Proteomic analysis of post-translational modifications. Nature biotechnology 21, 255-261.

Marchler-Bauer, A., Zheng, C., Chitsaz, F., Derbyshire, M.K., Geer, L.Y., Geer, R.C., Gonzales, N.R., Gwadz, M., Hurwitz, D.I., Lanczycki, C.J., Lu, F., Lu, S., Marchler, G.H., Song, J.S., Thanki, N., Yamashita, R.A., Zhang, D., Bryant, S.H., 2013. CDD: conserved domains and protein three-dimensional structure. Nucleic Acids Res 41, D348352.

Miller, L.C., Laegreid, W.W., Bono, J.L., Chitko-McKown, C.G., Fox, J.M., 2004. Interferon type I response in porcine reproductive and respiratory syndrome virusinfected MARC-145 cells. Arch Virol 149, 2453-2463.

Miller, L.C., Zanella, E.L., Waters, W.R., Lager, K.M., 2010. Cytokine protein expression levels in tracheobronchial lymph node homogenates of pigs infected with pseudorabies virus. Clin Vaccine Immunol 17, 728-734.

Pierleoni, A., Martelli, P.L., Casadio, R., 2011. MemLoci: predicting subcellular localization of membrane proteins in eukaryotes. Bioinformatics 27, 1224-1230. 
Sallman Almen, M., Bringeland, N., Fredriksson, R., Schioth, H.B., 2012. The dispanins: a novel gene family of ancient origin that contains 14 human members. PLoS One 7, e31961.

Siegrist, F., Ebeling, M., Certa, U., 2011. The small interferon-induced transmembrane genes and proteins. Journal of interferon \& cytokine research : the official journal of the International Society for Interferon and Cytokine Research 31, 183-197.

Solorzano, A., Webby, R.J., Lager, K.M., Janke, B.H., Garcia-Sastre, A., Richt, J.A., 2005. Mutations in the NS1 protein of swine influenza virus impair anti-interferon activity and confer attenuation in pigs. J Virol 79, 7535-7543.

Straw, B.E., 1999. Diseases of swine, 8th ed. Iowa State University Press, Ames, Iowa. Tamura, K., Peterson, D., Peterson, N., Stecher, G., Nei, M., Kumar, S., 2011. MEGA5: molecular evolutionary genetics analysis using maximum likelihood, evolutionary distance, and maximum parsimony methods. Mol Biol Evol 28, 2731-2739.

Torremorell, M., Allerson, M., Corzo, C., Diaz, A., Gramer, M., 2012. Transmission of Influenza A Virus in Pigs. Transbound Emerg Dis.

Van Reeth, K., Labarque, G., Nauwynck, H., Pensaert, M., 1999. Differential production of proinflammatory cytokines in the pig lung during different respiratory virus infections: correlations with pathogenicity. Res Vet Sci 67, 47-52.

Vincent, A.L., Ma, W., Lager, K.M., Janke, B.H., Richt, J.A., 2008. Swine influenza viruses a North American perspective. Advances in virus research 72, 127-154. Vincent, A.L., Swenson, S.L., Lager, K.M., Gauger, P.C., Loiacono, C., Zhang, Y., 2009. Characterization of an influenza A virus isolated from pigs during an outbreak of 
respiratory disease in swine and people during a county fair in the United States.

Veterinary Microbiology 137, 51-59.

Waterhouse, A.M., Procter, J.B., Martin, D.M., Clamp, M., Barton, G.J., 2009. Jalview

Version 2--a multiple sequence alignment editor and analysis workbench. Bioinformatics

$25,1189-1191$.

Yount, J.S., Moltedo, B., Yang, Y.Y., Charron, G., Moran, T.M., Lopez, C.B., Hang,

H.C., 2010. Palmitoylome profiling reveals S-palmitoylation-dependent antiviral activity of IFITM3. Nat Chem Biol 6, 610-614. 


\section{Tables}

Table 1. IFITM primers.

\begin{tabular}{|c|c|c|c|c|}
\hline PCR primers & Sequence $5^{\prime}-3^{\prime}$ & Len. & $\mathrm{Tm}$ & Amplicon (bp) \\
\hline F-IFITM1-197 & CTTCTGACATCCAGACACAGC & 21 & 59 & 295 \\
\hline R-IFITM1-491 & GTCTCCCACCATCTTCCGGT (iden. to 2,3, ILs) & 20 & 61 & \\
\hline F-IFITM2-128 & CGGTGATCAACATCCGAAGCG (iden. to 3, 1L1, 1L2, 1L4 and 3L2) & 21 & 62 & 253 \\
\hline F-IFITM2-380 & ACAAACACCAGAAGAACAGTGGC (iden. to 1) & 23 & 61 & \\
\hline F-IFITM3-173 & TCTGGTCCCTGTTCAACACC (iden. to $1,2,3 \mathrm{Ls}$ ) & 20 & 59 & 209 \\
\hline R-IFITM3-381 & GCCAGTGGTGCAAACGATG & 19 & 60 & \\
\hline F-IFITM1L1-384 & ATGGTGGGAGACATCACTGG (iden. to 2, 1L3) & 20 & 59 & 286 \\
\hline R-IFITM1L1-669 & GAACCCAGTTGTGGACAGGT (iden. to 1) & 20 & 59 & \\
\hline F-IFITM1L2-389 & GGTGGGAGACATCATTGGGG & 20 & 59 & 285 \\
\hline R-IFITM1L2-635 & TGAACCCAGTTGTGGACAGG & 20 & 60 & \\
\hline F-IFITM1L3-106 & GGTTCAGCTCCCATGACCAG & 20 & 60 & 276 \\
\hline R-IFITM1L3-381 & TGCAAACACCAGAAGAGCGA (iden. to 1, 2, ILs) & 20 , & 60 & \\
\hline F-IFITM1L4-473 & GTCGCTCTTCTGGTGTTTGC & 20 & 59 & 269 \\
\hline R-IFITM1L4-741 & GGCGAGCCTGTAACTTCTCT & 20 & 59 & \\
\hline F-IFITM5-195 & CAAGGCCCGAGATCAGAAGG & 20 & 60 & 204 \\
\hline R-IFITM5-398 & GAGTCGTCGAACTTGGTGCT & 20 & 60 & \\
\hline F-IFITM3L1-93 & ССTTCTTCACTGGTGCCCAT & 20 & 59 & 238 \\
\hline R-IFITM3L1-330 & TCAGGGCCCACCTTCACG & 18 & 61 & \\
\hline F-IFITM3L2-115 & TGATCAAGAGCCAGCACGAG & 20 & 60 & 197 \\
\hline R-IFITM3L2-311 & GGGCATGGCCACCTTCA & 17 & 59 & \\
\hline
\end{tabular}

Table 2. Porcine IFITM gene locus and structures based on current swine genome assembly (Sscorfa 10.2).

\begin{tabular}{|c|c|c|c|c|c|c|c|c|}
\hline Gene locus & Symbol & Chromosome coordinates & RefSeq & ISRE & Exon 1 & Intron & Exon 2 & ESTs \\
\hline LOC100127358 & IFITM1 & SSC2: $162099157.162100564(-)$ & XM_003124230.1 & Yes & 464 & 623 & 321 & Yes \\
\hline LOC100620056 & IFITM2 & SSC2: Gene ID: $100620056(-)$ & NM_001246214.1 & Yes & 319 & N/A & 1219 & Yes \\
\hline LOC100518544 & IFITM3 & SSC2: $162072261.162072507(-)$ & NM_001201382.1 & Yes & 247 & 419 & 192 & Yes \\
\hline LOC100627004 & IFITM1L1 IFTIM1L2 & SSC2: $162339710.162341038(-)$ & XM_003354415.1 & Yes & 368 & 637 & 324 & Yes \\
\hline LOC100626247 & (4 transcript variants) & SSC2: $162076668.162094496(-)$ & XM_003354411.1 & Yes & $352(v 1)$ & $289(\mathrm{v} 1)$ & $324(v 1)$ & Yes \\
\hline LOC100621926 & IFTIM1L3 (3 exons) & SSC1: $296319106.296331356(+)$ & XM_003353647.2 & Yes & 40 & 1153 & 206 & No \\
\hline LOC100519082 & IFTIM1L4 & SSC2: $162095298.162097522(+)$ & XM_003124235.2 & Yes & 358 & 636 & 1230 & Yes \\
\hline LOC100518184 & IFITM5 & SSC2: $162116292.162117532(+)$ & XM_003124229.3 & No & 198 & 682 & 361 & Yes \\
\hline LOC100627180 & IFITM5L & SSC2: $162317991.162319234(-)$ & XM_003354416.2 & No & 201 & 682 & 361 & Yes \\
\hline LOC100627740 & IFITM3L1 (partial) & SSC2: $162353100.162354440(+)$ & XM_003354422.2 & Yes & 323 & 964 & 53 & No \\
\hline LOC100627649 & IFITM 3 L2 & SSC2: $162333055.162334436(+)$ & XM_003354421.1 & Yes & 302 & 987 & 91 & No \\
\hline
\end{tabular}

ISRE, interferon-stimulated response element in core promoter regions; ESTs, expressed sequence tags.

Table 3. Predicted subcellular localization of human and porcine IFITMs.

\begin{tabular}{|c|c|c|c|}
\hline & \multicolumn{3}{|c|}{ Subcellular localization ${ }^{\mathrm{a}}$} \\
\hline & HslPred & Euk-mPLoc & BaCelLo \\
\hline pIFITM1 & $\mathrm{CM}$ & $\mathrm{CM}$ & MT \\
\hline pIFITM2 & $\mathrm{CP}$ & CM & $\mathrm{CP}$ \\
\hline pIFITM3 & $\mathrm{CM}$ & CM & $\mathrm{CP}$ \\
\hline pIFITM1L1 & $\mathrm{CP}$ & CM & MT \\
\hline pIFITM1L2 & $\mathrm{CP}$ & CM & MT \\
\hline PIFITM1L3 & $\mathrm{CP}$ & CM & $\mathrm{EC}$ \\
\hline PIFITM1L4 & $\mathrm{CP}$ & $\mathrm{CM}$ & MT \\
\hline pIFITM3L1 & $\mathrm{CP}$ & $\mathrm{CM}$ & $\mathrm{CP}$ \\
\hline pIFITM3L2 & MT & CM & $\mathrm{EC}$ \\
\hline pIFITM5 & $\mathrm{CP}$ & EC & $\mathrm{CP}$ \\
\hline pIFITM5L & $\mathrm{CP}$ & EC & $\mathrm{CP}$ \\
\hline hIFITM1 & $\mathrm{CM}$ & $\mathrm{CM}$ & $\mathrm{CP}$ \\
\hline hIFITM2 & $\mathrm{CM}$ & CM & $\mathrm{CP}$ \\
\hline hIFITM3 & $\mathrm{CM}$ & $\mathrm{CM}$ & $\mathrm{CP}$ \\
\hline hIFITM5 & $\mathrm{CP}$ & EC. MT & $\mathrm{CP}$ \\
\hline
\end{tabular}

a Predicted with three programs for eukaryotic proteins using hybrid approach (Hslpred), or algorithms based on a decision tree of several support vector machines (Euk-mPloc and MemiLoci).CP, cytoplasmic protein; CM, cell membrane; EC, extracellular; MT, Mitochondrial protein. 
Figures

(Human chromosome 11)

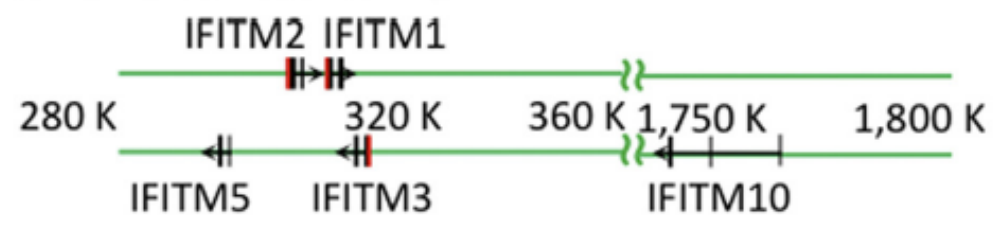

(Mouse chromosome 7)

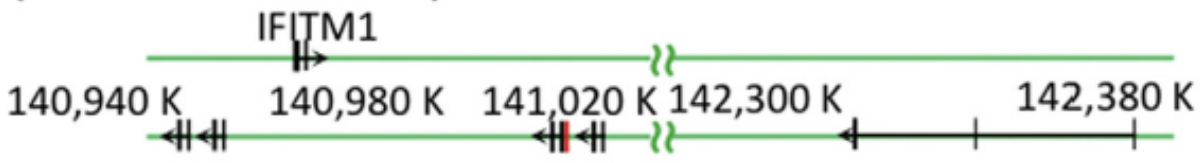

IFITM5 IFITM2 IFITM3 IFITM6

IFITM10

(Swine chromosome 2)

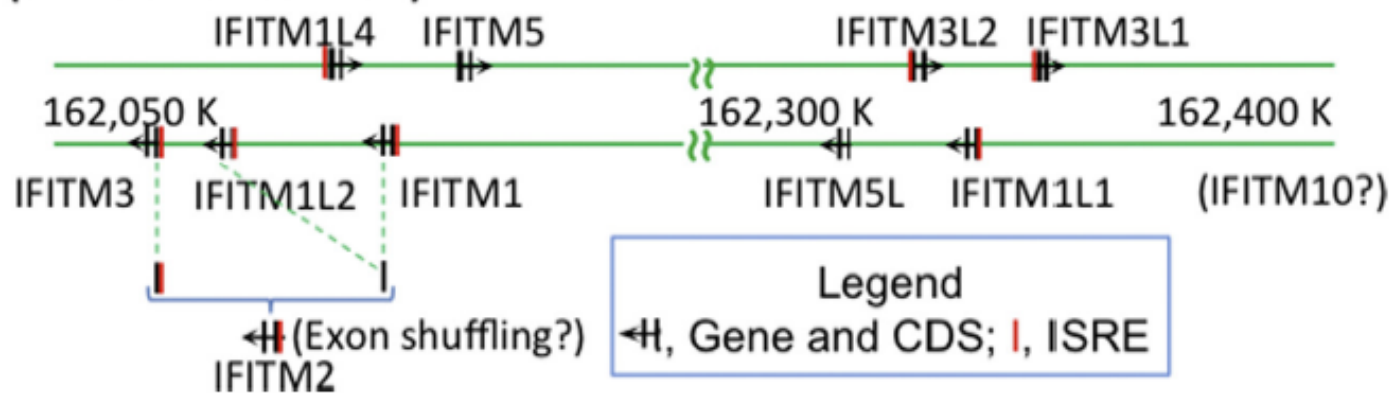

Figure 1. Chromosomal location of IFITM genes and the existence of interferonstimulated response element (ISRE, red bars) in their putative proximal promoter region. Green lines represent two strands of chromosomal DNA and black vertical bars represent exons of IFITM genes with the orientation of transcription indicated by the arrows. Human and mouse IFITM gene information was adapted from Siegrist et al., 2011, with modification. A piece of sequence on an unplaced genomic scaffold (NW_003541064.1, Sscrofa 10.2) was detected to show $100 \%$ identity to N-terminal $\sim 160 \mathrm{nt}$ of human IFITM10. 


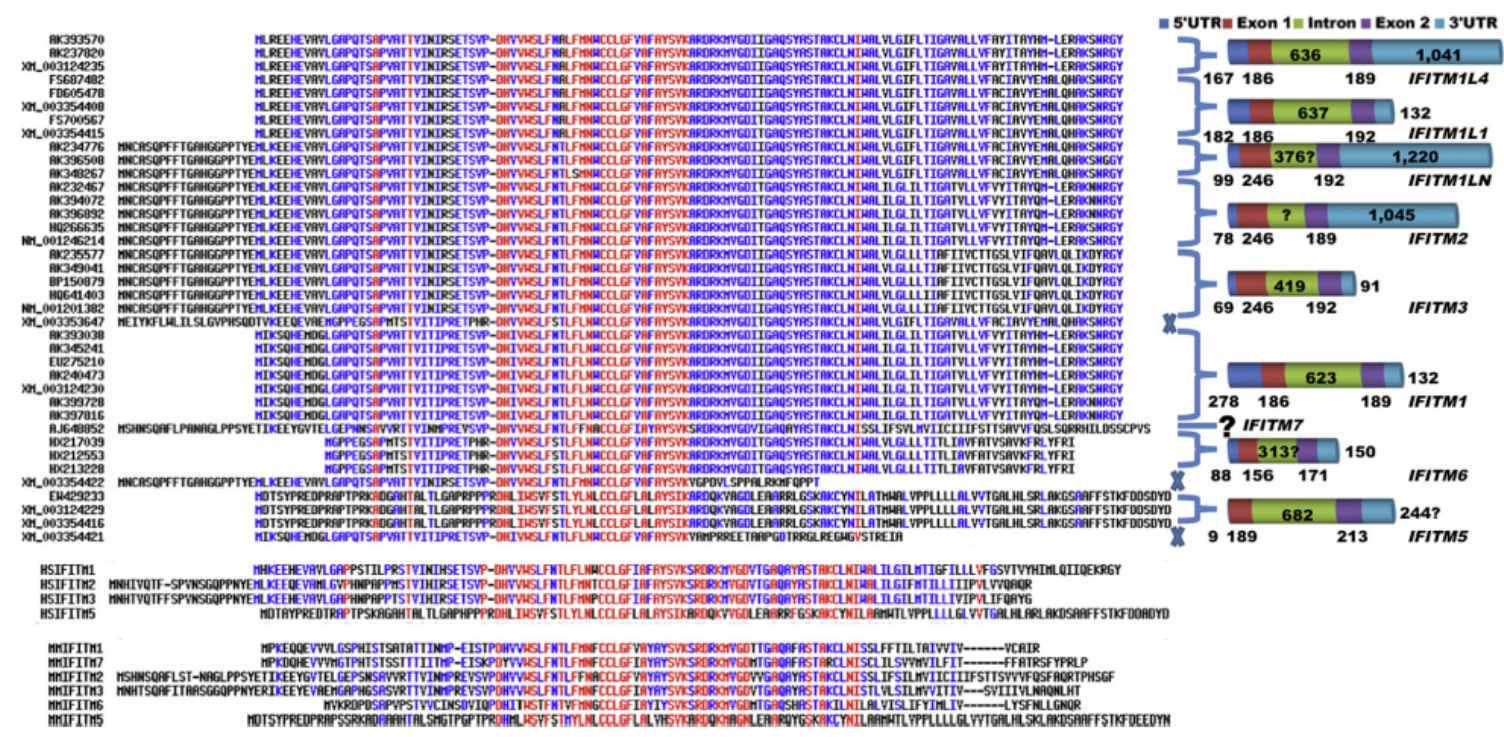

Figure 2. Annotation of IFITM family member in pigs with amino acid sequences and their genomic organizations. The 5'UTR, exon 1, intron, exon 2 and 3'UTR were proportionally drawn according to their actual sizes if known. '?' indicates a partially known region or a totally unknown region in size. "X" means that these model RefSeqs have no EST or non-RefSeq RNA evidence. Both human and mouse information are included. 


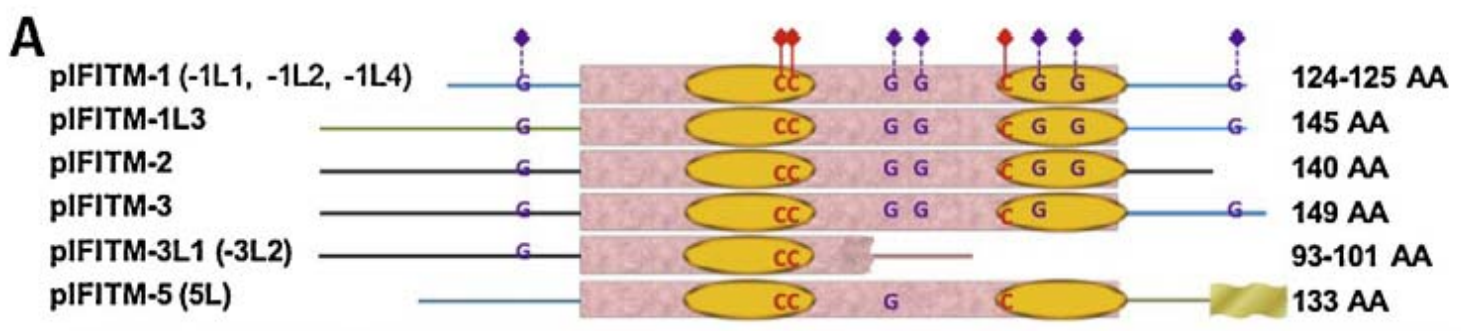

\begin{tabular}{|c|c|c|c|}
\hline$\square 225$ & $\Longrightarrow$ & $\mathrm{Ca} 2+$ & Conserved cysteine $(\mathrm{C})$ or glycine $(\mathrm{G})$ residues \\
\hline $\begin{array}{l}\text { CD225 } \\
\text { domain }\end{array}$ & $\begin{array}{l}\text { Transmembrane } \\
\text { domain }\end{array}$ & $\begin{array}{l}\mathrm{Ca2+} \\
\text { binding domain }\end{array}$ & $\begin{array}{l}\text { potentially involved in posttranslational } \\
\text { modification for membrane localization }\end{array}$ \\
\hline
\end{tabular}

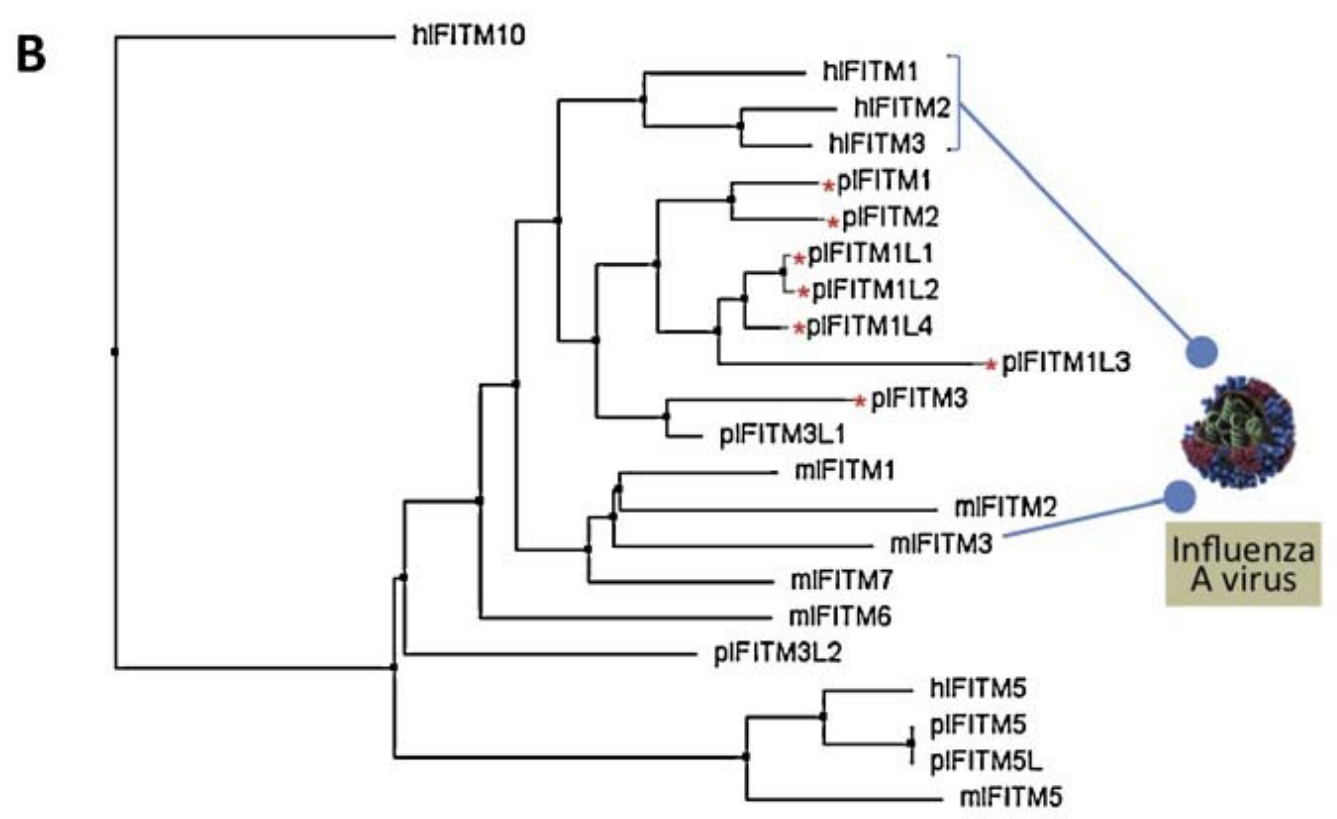

Figure 3. (A) Sequence and domain structure analyses of porcine IFITM proteins. All porcine IFITM proteins are centered by a CD225 functional domain of $\sim 90$ AA nearly flanked by two transmembrane (TM) domains, except the two IFITM3L1 and 3L2 having C-terminal truncated CD225 and only one TM domain. The diversity of N-terminal and C-terminal sequence among all isoforms is depicted with line fragments of different color and length. (B) Phylogenic analysis of human, mouse and porcine IFITM proteins rooted using human IFITM10. All IFITMs from the three species have been evolved from a closer ancestor than IFITM5 proteins that form into a separate ortholog cluster. The mammalian IFITM isoforms that have identified antiviral activity against influenza viruses are depicted with ball lines; and asterisks $\left(^{*}\right)$ label porcine IFITMs predictably to have anti-influenza activity. Species abbreviation: $h$, human; $m$, mouse and p, pig. 

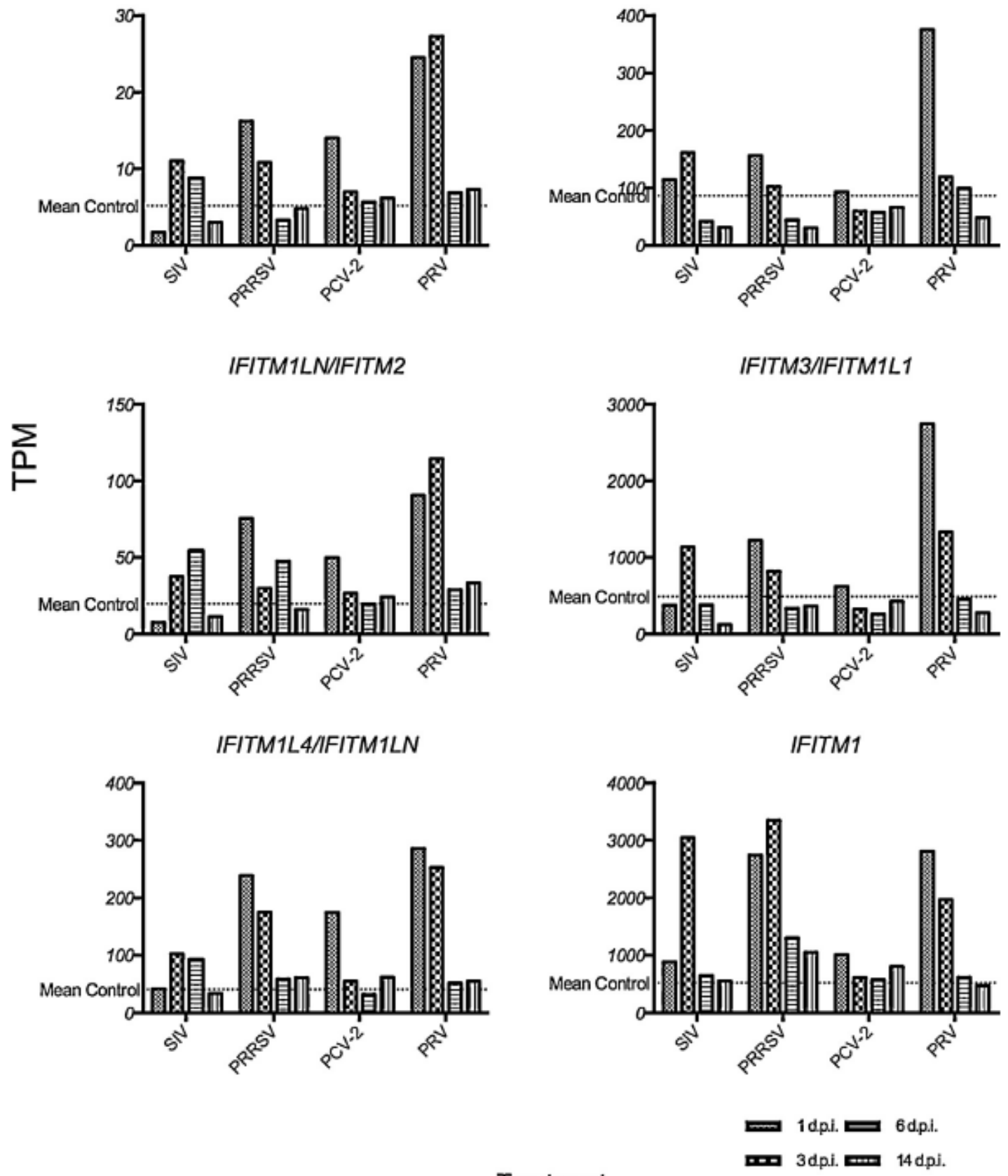

Treatment

Figure 4. Expression dynamics of IFITM family members in TBLN samples from pigs infected with SIV, PRV, PCV2 and PRRSV at 1, 3, 6 and 14 dpi. Six porcine IFITM genes were transcribed, with IFITM1, IFITM3/IFITM1L1abundantly expressed and upregulated at 3 dpi in the TBLN of SIV-infected pigs. Q, significantly different TPM (95\% confidence interval) from control mean; IFITM, interferon induced transmembrane proteins; TPM, transcripts per million tags. 

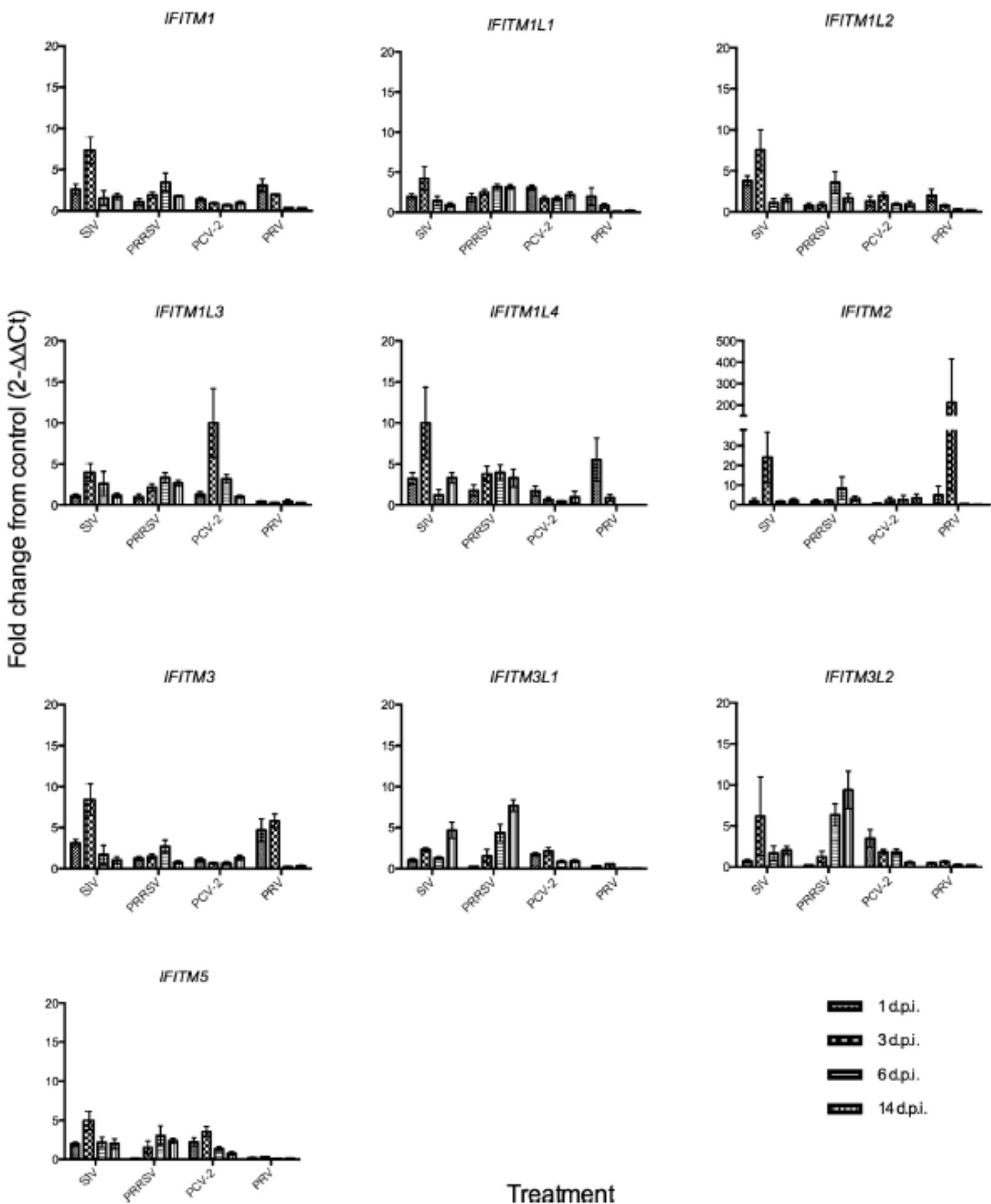

Figure 5. Real-time RT-PCR

Validation by real-time RT-PCR on RNA from the individual samples used in the DGETP analysis of selected IFITM transcripts showing differential transcript abundance. Fold change from the mean control transcript abundance $\left(2^{-\Delta \Delta \mathrm{Ct}}\right)$ (left $y$ axis) are shown for transcripts IFITM1, IFITM1L1, IFITM1L2, IFITM1L3, IFITM1L4, IFITM2, IFITM3, IFITM3L1, IFITM3L2 and IFITM5 normalized to the $18 \mathrm{~S}$ endogenous control. 

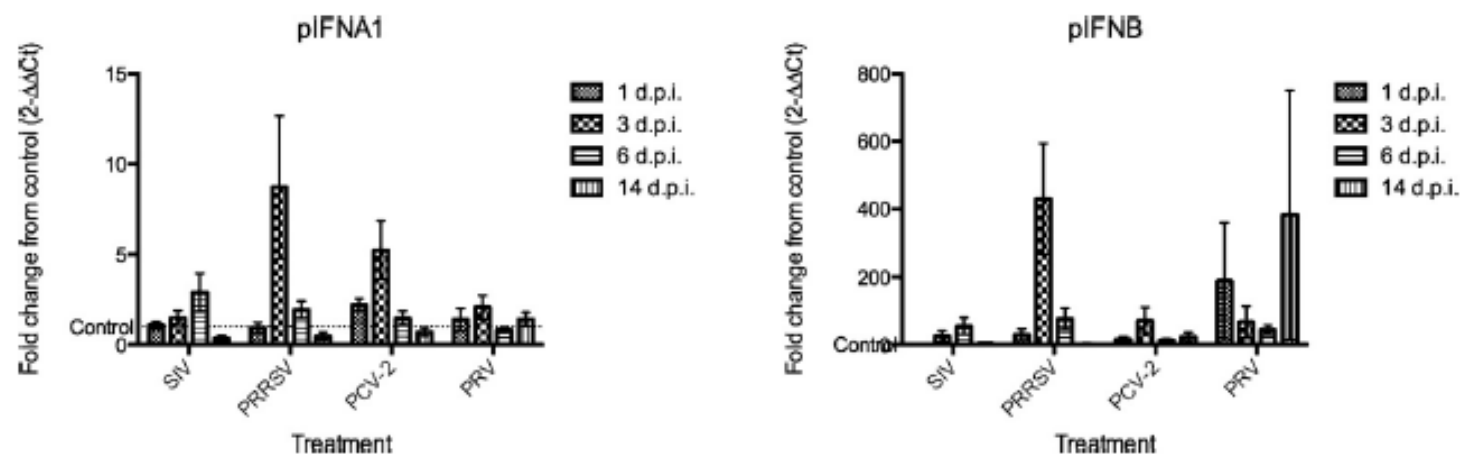

Figure 6. IFN- $\alpha_{1}$ and IFN- $\beta$ transcript abundance

Real-time RT-PCR on RNA from the individual samples used in the DGETP analysis of IFN- $\alpha_{1}$ and IFN- $\beta$ transcripts showing differential transcript abundance. Fold change from the mean control transcript abundance $\left(2^{-\Delta \Delta \mathrm{Ct}}\right)$ (left $y$ axis) are shown for IFN- $\alpha_{1}$ and IFN- $\beta$ transcripts normalized to the $18 \mathrm{~S}$ endogenous control. 